\title{
Experimental Investigation and Numerical Modelling of Flow Characteristics of Non- Rotating Twin Screw Model
}

\author{
Sylva Drábková ${ }^{1,}$, Marian Bojko ${ }^{1}$, Josef Veselý $^{2}$, and Rostislav Zapletal ${ }^{2}$ \\ ${ }^{1}$ VŠB-TU Ostrava, Faculty of Mechanical Engineering, Department of Hydromechanics and Hydraulic \\ Equipment, 17. listopadu 2172/15, Ostrava-Poruba 70800, Czech Republic \\ ${ }^{2}$ Hydrosystem project a. s., tř. Kosmonautů 1103/6a, Hodolany, 77900 Olomouc, Czech Republic
}

\begin{abstract}
Twin-screw pumps employ clearances between both screws and screw rotors and housing, which cause backflow as function of pressure differential. Reduction of this flow can be reached by proper geometry design. For the experimental investigation, the scaled model $1: 2$ of the screws section was produced with trapezoidal tooth profile in two modifications differing in tooth width and pitch. Measurement of flow characteristics of non-rotating twin-screw model was carried out for validation and possible corrections of the 3D CFD model. The testing was done with non-Newtonian liquid met in the food industry and additionally also with water. Experimental data were partly compared with results obtained from numerical simulations.
\end{abstract}

\section{Introduction}

Twin-screw pumps provide good operating efficiencies in comparison with centrifugal pumps when handling viscous liquids such as those met in food industry. However, rheological characteristics of the pumped materials significantly influence the performance of a twin-screw pump and are important in the specification of screws design parameters. Numerical CFD analysis presented in [1] focused on investigation of the influence of the screw geometry, clearances and non-Newtonian behaviour of the fluid. The obtained results proved the effect of all tested parameters. Computational modelling of the non-Newtonian liquid flow through the simplified model of a pair of screws showed significant penetrations of masses through clearances from higher pressure to lower pressure, both for screw thread geometries with minimized and enlarged clearances. This penetrations cause reduction in the volumetric efficiency of the screw pump.

In 2019 in agreement with HYDROSYSTEM project a.s. it was decided to continue this investigation and prepare physical experiment for validation and correction of the numerical model.

\footnotetext{
Corresponding author: sylva.drabkova $@$, vsb.cz
} 


\section{Model setup}

The production of the test model of screws in the scale 1:2, including subsequent modifications, was provided by the company SIGMA PUMPY HRANICE, s.r.o. The screws were produced on a CNC lathe MAS Kovosvit S80i from steel 11700 (see Figure 1).

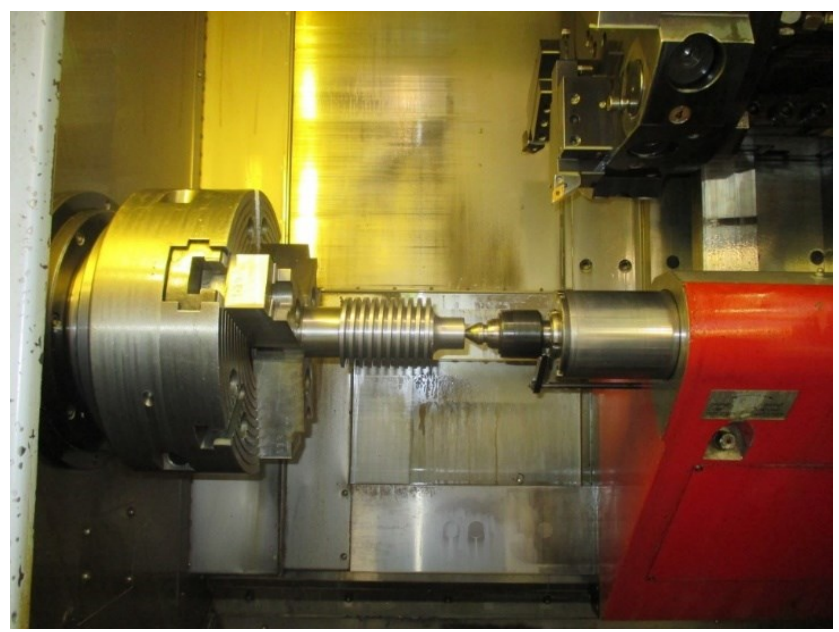

Fig. 1. Production of the model screw on a CNC lathe MAS Kovosvit S80i.

The design of the screws employed the trapezoidal tooth profile in two variants, illustrated in Figure 2.

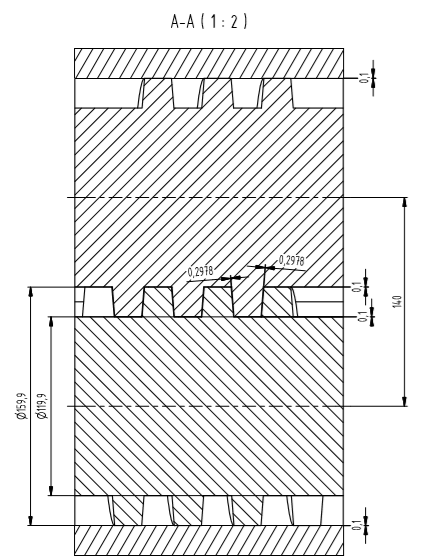

a) geometry variant $\mathbf{A}$

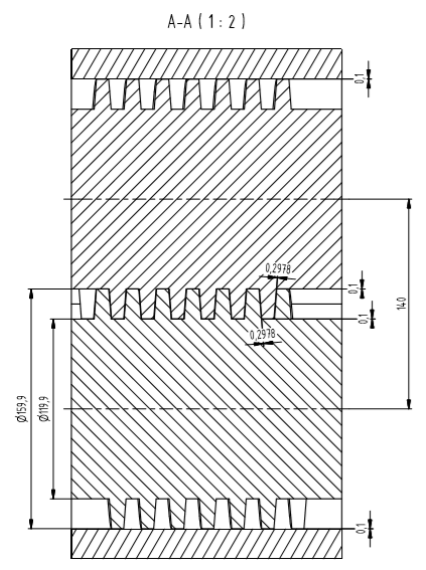

b) geometry variant $\mathbf{B}$

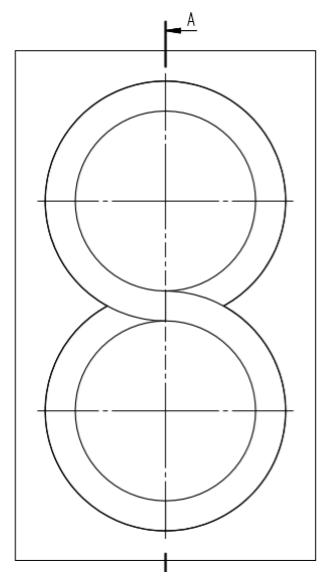

Fig. 2. Scheme of the twin screw section - geometry variant A and B.

Variant A with nominal profile of model 10x10 (mm) with a pitch of $20 \mathrm{~mm}$ and with the number of 4 threads - corresponds to the part of the screws $20 \times 20(\mathrm{~mm})$, with a pitch of $40 \mathrm{~mm}$ (see Figure 2a),

Variant B with a nominal profile of the model $5 \times 10(\mathrm{~mm})$ with a pitch of $10 \mathrm{~mm}$ and with the number of 8 threads - corresponds to a screw section $10 \times 20(\mathrm{~mm})$, with a pitch of $20 \mathrm{~mm}$. (see Figure $2 \mathrm{~b}$ ). 
In order to investigate the effects of the different clearance size on the mass flow rate, the circumferential clearance was varied by $0.05 \mathrm{~mm}$ and investigated separately for both geometries.

The screws were placed into the housing with very small clearances. Figure 3 shows the prepared assembly (only one screw is drawn). The basic parameters of screws geometry for model variants $\mathrm{A}$ and $\mathrm{B}$ are defined in Table 1 .

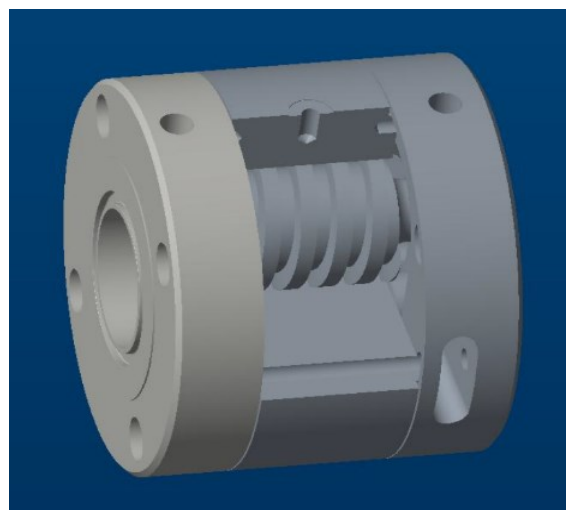

Fig. 3. Assembly of a test screws in housing.
Table 1. Geometrical parameters of the screws $(\mathrm{mm})$.

\begin{tabular}{|l|c|c|}
\hline & $\begin{array}{c}\text { Geometry } \\
\text { version A: }\end{array}$ & $\begin{array}{c}\text { Geometry } \\
\text { version B: }\end{array}$ \\
\hline External diameter & 79.85 & 79.85 \\
\hline Root diameter & 59.95 & 59.95 \\
\hline Channel depth & 10 & 10 \\
\hline Aver. channel width & 10 & 5 \\
\hline Pitch & 20 & 10 \\
\hline $\begin{array}{l}\text { Circumferential } \\
\text { clearance }\end{array}$ & $0.05(0.1)$ & $0.05(0.1)$ \\
\hline Flank clearance & 0.15 & 0.15 \\
\hline Root clearance & 0.1 & 0.1 \\
\hline
\end{tabular}

\section{Non - Newtonian characteristics of transported material}

During the test, three mass samples were taken, for which the actual content of the dry matter was defined and the rheogram was measured with a rotary viscometer. Shear thinning behaviour of the transported material was described by the Power law model, which defines two parameters, the consistency $k$ and the flow index $n$ in a form:

$$
\eta=k \gamma^{n-1}
$$

where consistency $k$ is a constant of proportionality, the flow index $n$ defines the degree to which the fluid is shear thinning. (see Figure 4) [2].

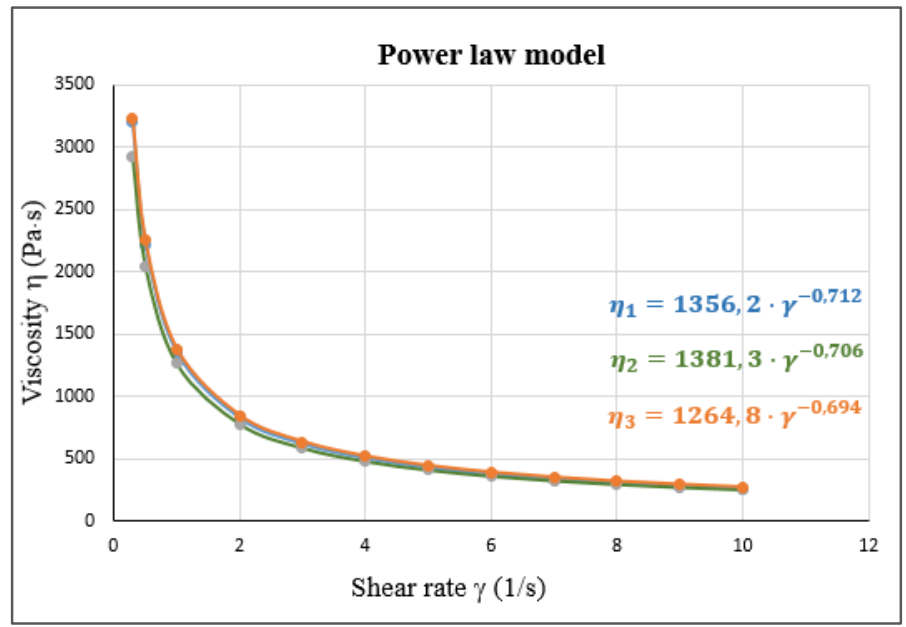

Fig. 4. Power law characteristics $\eta=\mathrm{f}(\gamma)$ of transported material. 
Corresponding shear stress described by equation (2) is presented in Figure 5.

$$
\tau=k \gamma^{n}
$$

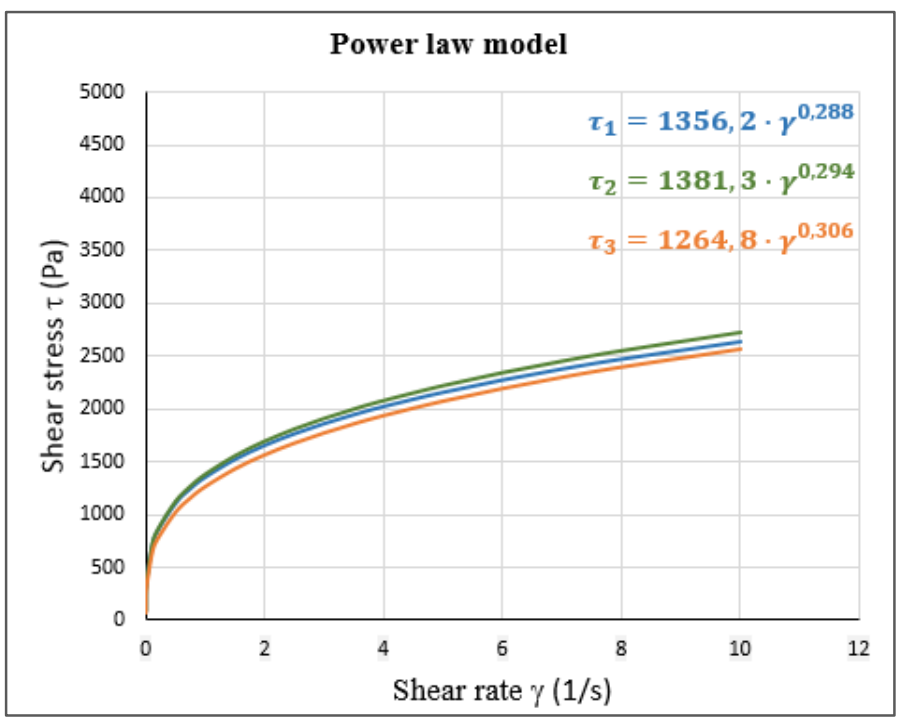

Fig. 5. Corresponding shear stress $\tau=\mathrm{f}(\gamma)$.

Slightly non-Newtonian materials have a power law index value between 0.7 and 1 and those classified as highly non-Newtonian have values between 0 and 0.7 [2].

\section{Experimental measurements}

\subsection{Experimental test rig}

The assembly of the test screws in the housing was connected to the high pressure pumping system based on a two-chamber dispenser. In this system, a high-pressure plunger pump equipped with continuous speed control via frequency converter was used as a source of constant flow rate.

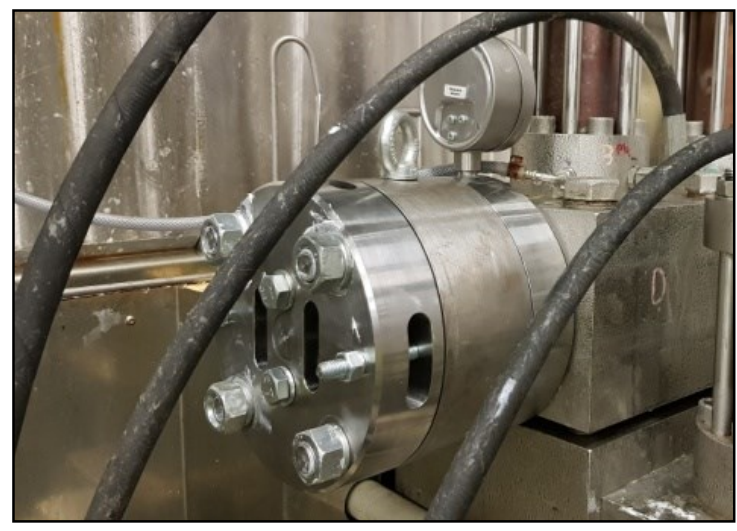

Fig. 6. Detail of the screws assembly built into the high pressure pumping system. 
The value of the pressure loss was estimated from the measured overpressure at the mass entrance into the screws of the tested assembly. The pressure behind the screws was not measured as the mass from the test set flowed into the atmosphere through the holes whose flow area was an order of magnitude higher than the flow area of the screw sample clearances.

\subsection{Measurement of flow characteristics with non-Newtonian liquid}

The flow through the screw model was measured with non-Newtonian fluid with low flow index (defined in chapter 3). The measurement was carried out for several values of mass flow-rate controlled with the plunger pump. The pressure measured at the mass entrance into the model was monitored in time and the average pressure value was calculated from the time record. Finally, the dependence $\Delta p=f(Q)$ was plotted from these averages.

The results for geometry variant A - model with nominal tooth profile 10x10 $(\mathrm{mm})$, pitch of $20 \mathrm{~mm}$, standard and enlarged clearances, are summarized in Figure 7 and 8 . It can be seen that the enlargement of circumferential clearance increases leakage amount.

Unfortunately, the maximum operating pressure of the system did not enable to measure the dependence $\Delta p=f(Q)$ for half-pitch spindles (geometry variant $\mathrm{B}$ with a nominal tooth profile of $5 \times 10 \mathrm{~mm}$, pitch of $10 \mathrm{~mm}$ ). The pressure record for the minimum mass flow-rate showed a steep increase reaching the value of the maximum operating pressure. At the same time, the flow decrease was observed due to the overload of the frequency converter at low speed.

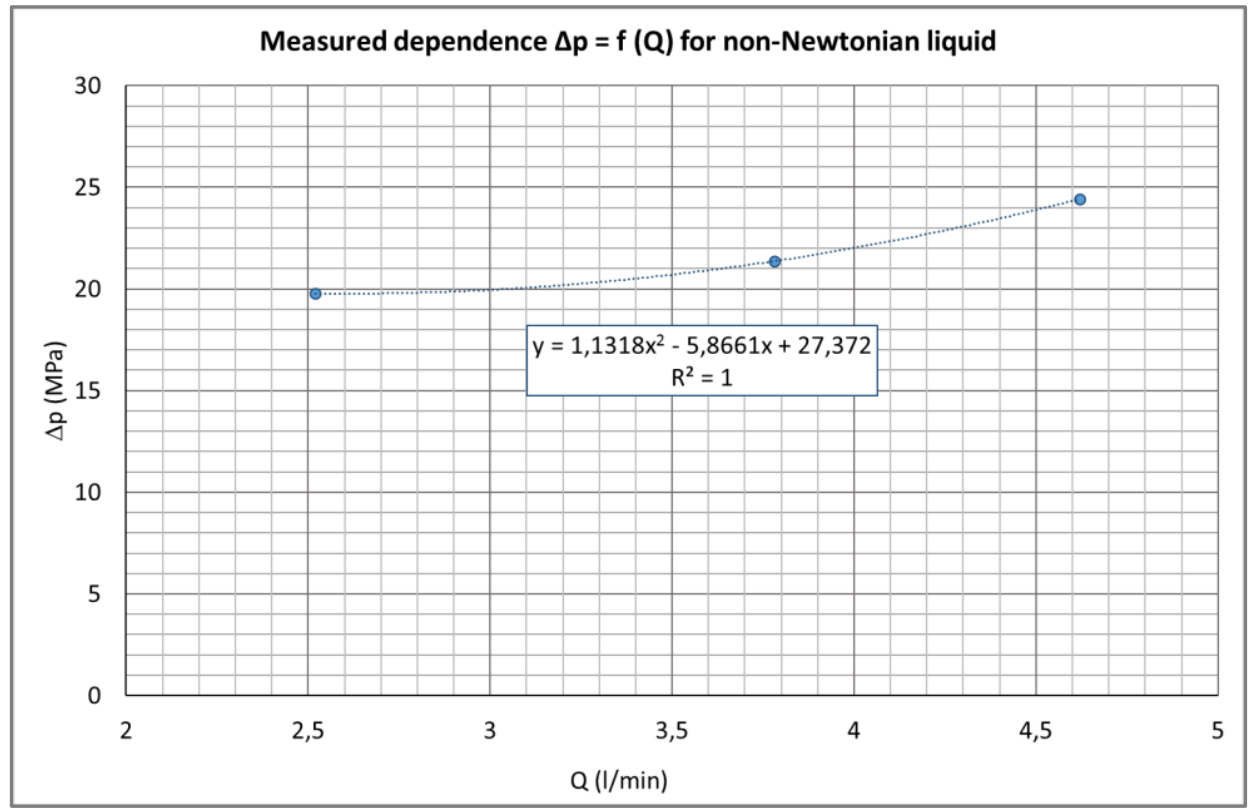

Fig. 7. Pressure loss for static twin-screw model 1: 2, geometry A, standard clearances $0.05 \mathrm{~mm}$. 


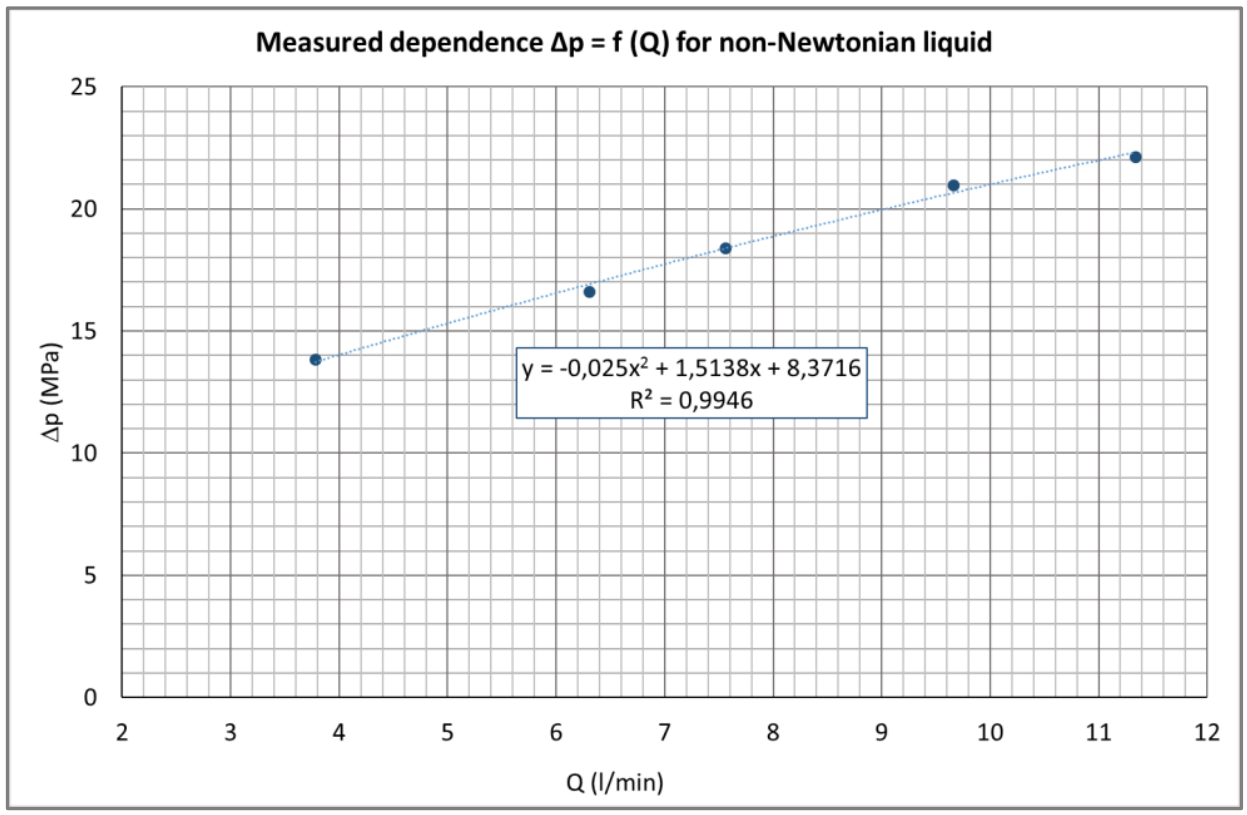

Fig. 8. Pressure loss for static twin-screw model 1: 2, geometry A, enlarged clearances $0.1 \mathrm{~mm}$.

\subsection{Measurement of flow characteristics with water}

Installation of the test circuit and measurement of the test model on water took place later in November 2019. The experimental setup contained plunger pump as a source of the flow-rate, flow meter, manometers, bypass control valve and pressure hoses with connections. Water was fed into the system using the plunger pump with a flow rate of $82 \mathrm{l} / \mathrm{min}$ without frequency converter. The required flow was set with bypass control valve. The flow rate was measured by a flow meter built into the waste (drain) branch of the test circuit. The pressure was measured with manometers - the expected range up to $5 \mathrm{MPa}$ (at the entry) and up to $1 \mathrm{MPa}$ (at the outlet).

The measurement was carried out both for geometry variant A and B with standard and enlarged clearances. Figure 9 and 10 show the $\Delta p-Q$ characteristic for the geometry variant A (course pitch) and B (fine pitch) with standard and enlarged circumferential clearances. The characteristic exhibits polynomial behaviour typical for the turbulent flows. 


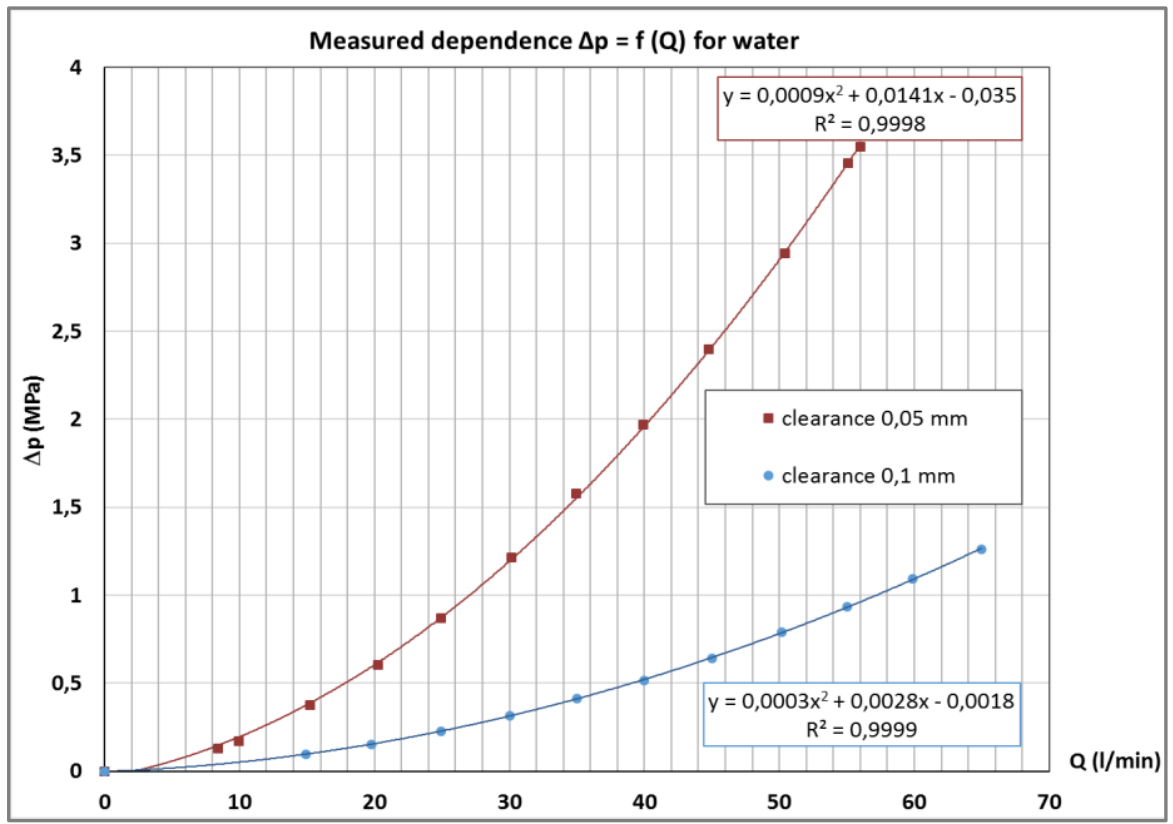

Fig. 9. Pressure loss for geometry A, standard and enlarged clearances.

The twin screw model with geometry variant B with (nominal profile of the model $5 \times 10 \mathrm{~mm}$ with a pitch of $10 \mathrm{~mm}$ and 8 threads generated higher pressure loss both in case of standard and enlarged clearances (see Figure 10).

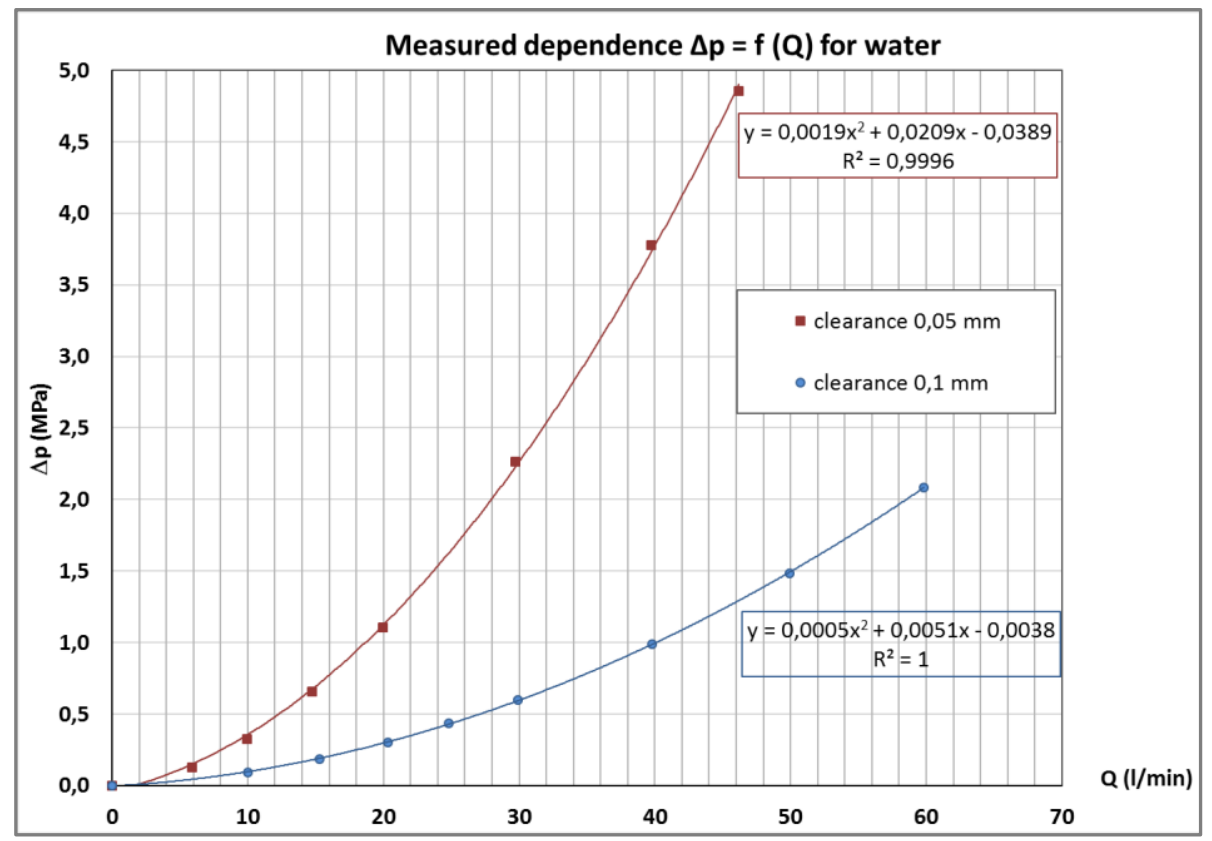

Fig. 10. Pressure loss for geometry $\mathbf{B}$, standard and enlarged clearances. 


\section{Mathematical model of the fluid flow}

Mathematical model of the isotermal fluid flow is generally defined by basic balance equations such as continuity equations and Navier-Stokes equations [3]:

Mass conservation (continuity equation)

$$
\frac{\partial(\rho)}{\partial t}+\nabla \cdot(\rho \vec{u})=0
$$

Momentum conservation (Navier- Stokes equation)

$$
\frac{\partial(\rho \vec{u})}{\partial t}+\nabla \cdot(\rho \vec{u} \vec{u})=-\nabla p+[\nabla \cdot \overline{\bar{\tau}}]+\rho \vec{a}+S_{m}
$$

where $p$ is the static pressure, $\overline{\bar{\tau}}$ is the stress tensor, $\rho \vec{a}$ is the body force and $S_{m}$ can contain other model-dependent source terms such as porous-media and user-defined sources.

This basic mathematical model is further extended with additional transport equations when the flow is turbulent [4]. Treatment of the underlying physical laws and the construction and effective use of numerical procedures to describe the behavior of the dynamics of physical flow. treatment of the underlying physical laws and the construction and effective use of numerical procedures to describe the behavior of the dynamics of physical flow.

\subsection{Numerical modelling of non - Newtonian liquid flow}

Geometry variant A of the twin-screw model with enlarged clearances $0.1 \mathrm{~mm}$ was chosen for the comparison with experimental measurement. The geometry and computational grid were prepared in ANSYS DesignModeller [3] and are presented in Figure 11 and 12.

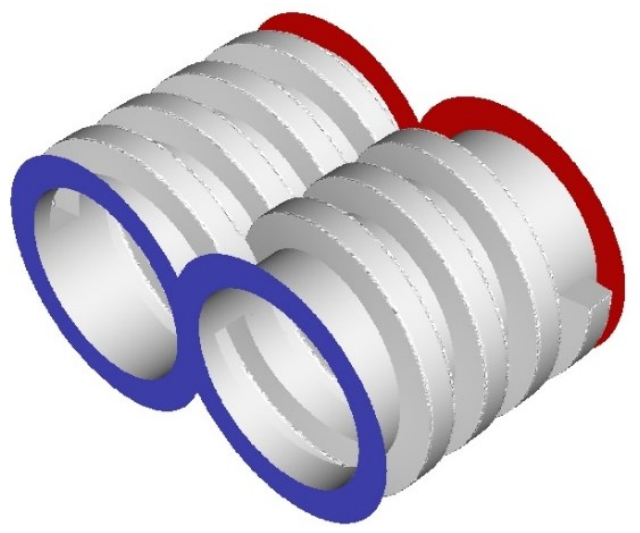

Table 2. Boundary conditions.

\begin{tabular}{|l|l|}
\hline Inlet & mass-flow rate \\
\hline Outlet & gauge pressure \\
\hline $\begin{array}{l}\text { Stationary } \\
\text { walls }\end{array}$ & $\begin{array}{l}\text { No-slip boundary } \\
\text { condition }(\mathrm{u}=0) .\end{array}$ \\
\hline
\end{tabular}

Fig. 11. The modelled geometry A with definition of Inlet ( blue) and Outlet (red).

Unstructured fine computational grid contained combination of hexagonal, tetrahedral and pyramidal elements. Number of grid elements defines Table 3. 


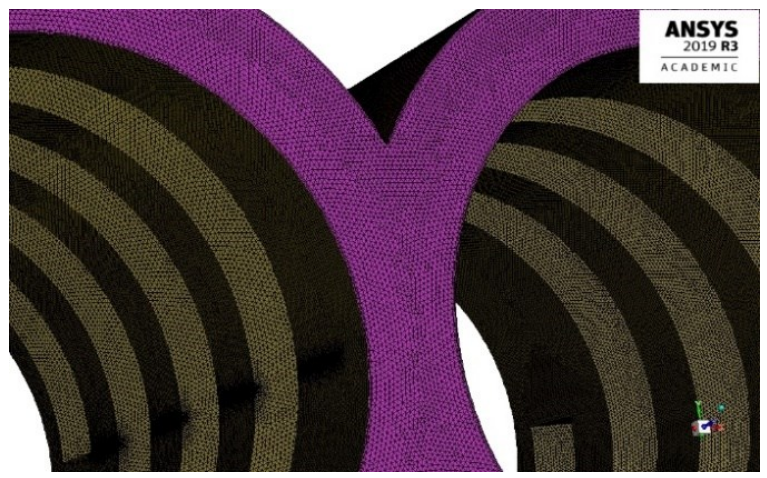

Table 3. Number of grid elements.

\begin{tabular}{|l|l|}
\hline \multicolumn{2}{|c|}{ Geometry variant A } \\
\hline $\begin{array}{l}\text { Standard } \\
\text { clearance } \\
0.05(\mathrm{~mm})\end{array}$ & 9951192 \\
\hline $\begin{array}{l}\text { Enlarged } \\
\text { clearance } \\
0.1(\mathrm{~mm})\end{array}$ & 9150256 \\
\hline
\end{tabular}

Fig. 12. Grid example of the fluid domain.

The flow of highly viscous non-Newtonian substance in the screws model without rotation was characterized as laminar, stationary, isothermal flow of incompressible liquid in a general three-dimensional region [5].

Rheology of transported non-Newtonian material was described with the power law:

$$
\eta_{1}=1356.2 \gamma^{-0,712}
$$

The density was $1.05 \mathrm{~kg} / \mathrm{dm}^{3}$ and temperature $15{ }^{\circ} \mathrm{C}$.

Calculated data were compared with measurement. It can be seen that numerical modelling predicted steeper increase of pressure loss with flow rate (see Figure 13).

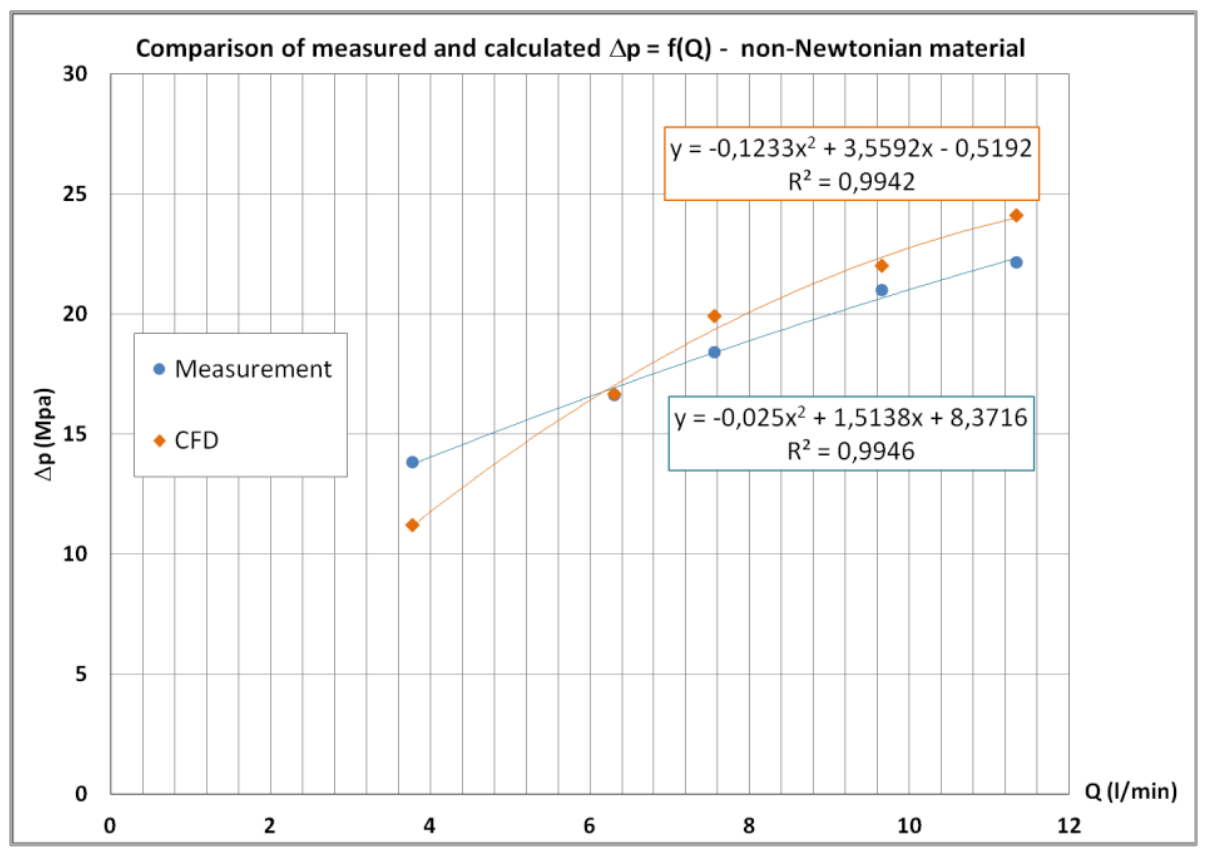

Fig. 13. Measured and calculated pressure loss for geometry A, enlarged clearances. 


\subsection{Numerical modelling of water flow}

The flow of water through the screws model without rotation was characterized as turbulent, stationary, isothermal flow of incompressible liquid. The geometry variant A with standard and enlarged clearances was chosen and the solution was carried out on the identical grid as in previous case.

Different turbulence models have been compared during this simulation. Finally, the $k$ $k l-\omega$ transition model proved to be most accurate in this situation. This model utilizes the approach of laminar kinetic energy in order to predict transition between laminar and turbulent flows. The $k-k l-\omega$ transition model is considered to be a three-equation eddyviscosity type, which includes transport equations for turbulent kinetic energy $\left(k_{\mathrm{T}}\right)$, laminar kinetic energy $\left(k_{\mathrm{L}}\right)$, and the inverse turbulent time scale $(\omega)$ [3].

Mass-flow inlet and pressure outlet were used for the inlet and outlet boundaries. The values were defined in the range obtained in experiment. The turbulence intensity was $1 \%$ and the hydraulic diameter was $0.07 \mathrm{~mm}$. Measured and calculated results are compared in Figure 14.

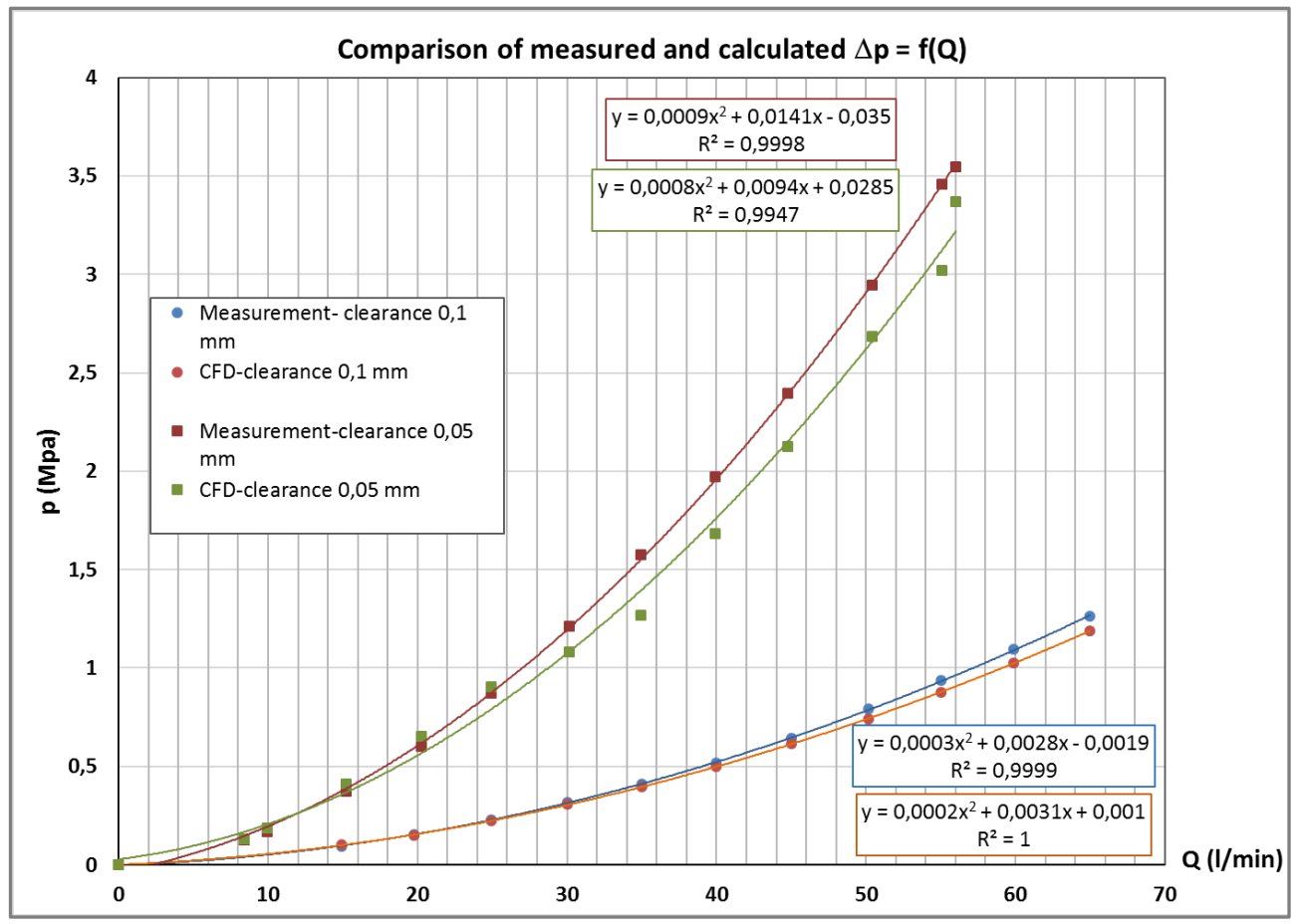

Fig. 14. Measured and calculated pressure loss for geometry A, standard and enlarged clearances, water.

\section{Conclusion and discussion}

Physical experiment and CFD analysis were applied to predict the flow through the designed non rotating twin screw model for a specific set of operating conditions, screw geometry and material properties. The liquid flows mainly through the circumferential clearance. The main objective was to define the pressure loss in dependence on the flow rate [5]. Non-Newtonian material was used as first, whose rheological properties were 
measured and described with a power law constitutive equation. The measurement was accompanied with limitations and only several points of the characteristic curve were measured for geometry variant A.

During the numerical simulations the accurate definition of rheology proved to play a critical role in CFD analysis and the effect of $n$ and $k$ on the pressure drop predictions were significant [1]. The agreement of the measured and calculated data was only partial. Numerical modelling predicted steeper increase of pressure loss with flow rate in comparison with measurement.

In the second experiment, water was used as the Newtonian liquid. Numerical simulations were very sensitive to applied model of turbulence from which the $k-k L-\omega$ proved to be the most effective [4]. In this case there was a good correlation between the experimental observations and numerical simulations for the enlarged circumferential clearance $0,1 \mathrm{~mm}$. In case of the clearance $0.05 \mathrm{~mm}$ the agreement was reached for lower values of the flow rate. In both cases CFD modelling underestimated the values of pressure drop in comparison with experimental measurement.

Computational experiments encompassing the screws rotation will be carried out as the next step for the further analysis of the twin screw pump performance [6].

\section{References}

1. M. Bojko, S. Drábková, J. Veselý, R. Zapletal, Numerical modelling of a nonNewtonian fluid in the twin-screw pump. Experimental Fluid Mechanics 2019. p. 6671 (2019)

2. J. I. Orisaleye, O. A. Adefuye, A. A. Ogundare, O.L. Fadipe, Parametric analysis and design of a screw extruder for slightly non-Newtonian (pseudoplastic) materials. Engineering Science and Technology. 21, Issue 2, Pages 229-237 (2018)

3. ANSYS Fluent User's Guide, Release 18.2, 2017 ANSYS, Inc.

4. ANSYS Fluent Theory Guide, Release 18.2, 2017 ANSYS, Inc.

5. M. Kozdera, M. Bojko, S. Drábková, M. Kozubková, Studying the interaction of liquid and solid in the flow of liquid in annulus by CFD analysis. Applied Mechanics and Materials, 630, p. 220-227 (2014)

6. A. Covas, A. Gaspar-Cunha, A computational investigation on the effect of polymer rheology on the performance of a single screw extruder, e-rheo. pt. 1, p. 41-62 (2001)

This work was supported by the project Trio FV40105 "Development and production of a prototype of a high-pressure screw pump for pumping highly viscous materials" funded by Ministry of Industry and Trade, Czech Republic. 